\title{
Microwave synthesis of copper oxide nanoparticles using tea leaf and coffee powder extracts and its antibacterial activity
}

\author{
Prasanta Sutradhar • Mitali Saha • Debasish Maiti
}

Received: 25 November 2013 / Accepted: 8 January 2014/Published online: 21 February 2014

(C) The Author(s) 2014. This article is published with open access at Springerlink.com

\begin{abstract}
Oxides of copper have been investigated for decades due to their unique semiconductor and optical properties. The review of literature revealed that very few reports are available on the synthesis of copper oxide nanoparticles using microorganisms and plant extracts. In this paper, we have reported the synthesis of copper oxide nanoparticles $(\mathrm{CuO})$ using tea leaf and coffee powder extracts under microwave irradiations. The synthesis was carried out by irradiating metal salt and the extracts of tea and coffee in 1:3 ratio in a microwave at $540 \mathrm{~W}$ for 7-8 min. The synthesized nanoparticles were characterized by Scanning electron microscope, X-ray diffraction, UVvisible spectroscopy and Fourier transform infrared spectroscopy. The antibacterial activity of these nanoparticles was tested against six human pathogenic microbes. It was interesting to find that these nanoparticles possess remarkable antibacterial activity against two human pathogenic bacteria. Moreover, the use of environmentally benign materials for the synthesis of $\mathrm{CuO}$ nanoparticles offers numerous benefits of eco-friendliness and compatibility for pharmaceutical and other biomedical applications.
\end{abstract}

Keywords Tea $\cdot$ Coffee $\cdot$ Microwave $\cdot$ SEM $\cdot$ FTIR

P. Sutradhar · M. Saha $(\bowtie)$

Department of Chemistry, National Institute of Technology,

Agartala 799046, Tripura, India

e-mail: mitalichem71@gmail.com

P. Sutradhar

e-mail: psdharrr@gmail.com

D. Maiti

Department of Human Physiology, Tripura University,

Agartala 799046, Tripura, India

\section{Introduction}

The development of rapid and reliable processes for the preparation of nanosized metal particles has attracted significant attention due to their unusual size-dependent optical and electronic properties. Till now, a large number of physical, chemical and biological methods were available to synthesize different types of nanoparticles [1-4]. However, it is a fact that reproducibility and stability of the nanoparticles with controlled size are very difficult to achieve by popular chemical reduction methods. Synthesis of nanoparticles using plant extracts is quite novel and leads to true green chemistry at a very affordable cost [5-12].

Oxides of copper have been investigated for decades due to their unique semiconductor and optical properties [1316]. Few studies have reported that copper nanoparticles exhibit excellent bactericidal properties [17-20]. Different methods have been available in the literature for the preparation of copper oxide nanoparticles, where flammable or corrosive reducing agent has been used such as titanium tetrachloride and hydrazine. Some wet chemical methods employed the toxic organic reactant such as ethylene glycol, while certain methods used additional reducing agent such as sodium tartrate [21-23]. In continuation of our earlier efforts for the synthesis of new carbon and metal nanoparticles for their applications in different fields [24-27], we have now reported the synthesis of nanosized copper oxide $(\mathrm{CuO})$ via a green route, using tea leaf and coffee powder extracts. The main aim was that the nanoparticles should be water-dispersible and stable in aqueous media for prolonged periods, to be useful in biological applications. Although the exact mechanism for the synthesis of nanoparticles using plant extracts has not been devised, but it was suggested that different polyol 
Scheme 1 The reaction for the formation of $\mathrm{CuO}$ nanoparticles<smiles>C#COc1cc([C@H]2Oc3cc(O)cc(O)c3C[C@H]2OC(=O)c2cc(O)c(O)c(O)c2)cc(O)c1O</smiles>

EGCG<smiles>O=C(O)c1cc(O)c(O)c(O)c1</smiles>

EGCG<smiles>[R]C#CC</smiles><smiles>O=C(O)c1cc(O)c(O)c(O)c1</smiles>

EGCG

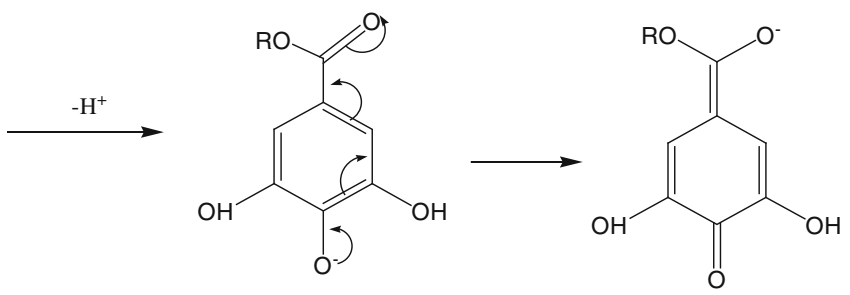

Semi dehydro-EGCG<smiles>O=C(O)C1=CC(=O)C(=O)C(O)=C1</smiles><smiles>O=C1CC(C(=O)O)CC(C(=O)O)C1=O</smiles>

Dehydro-EGCG

$$
\mathrm{Cu}^{2+}+2 \mathrm{e}^{-}
$$

components are responsible for the synthesis of nanoparticles. We have shown a possible mechanism about the formation of $\mathrm{CuO}$ nanoparticles from copper (II) ion.
Further, to realize the potential of $\mathrm{CuO}$ nanoparticles as antimicrobial agents, these were tested against six human pathogenic bacteria. 


\section{Experimental procedure}

Preparation of tea leaf and coffee powder extract

Two extracts were used to produce $\mathrm{CuO}$ nanoparticles. $20 \mathrm{~g}$ fine grounded powder of tea leaf and coffee powder were separately dissolved in $200 \mathrm{ml}$ of water and boiled for around $3 \mathrm{~h}$. After cooling at room temperature, these were centrifuged for $15 \mathrm{~min}$ and filtered. The filtrates were stored at $5-10{ }^{\circ} \mathrm{C}$ for further experiments.

Synthesis of $\mathrm{CuO}$ nanoparticles using tea leaf extract

Copper nitrate and tea leaf extract were taken in 1:3 ratio and the solution was subjected to microwave heating at $540 \mathrm{~W}$ which produced dark brown precipitate after 7-8 min. The precipitate was centrifuged, filtered and then dried in hot air oven for 4-5 h. The probable mechanism of the formation of $\mathrm{CuO}$ nanoparticles has been shown in Scheme 1.

Synthesis of $\mathrm{CuO}$ nanoparticles using coffee extract

Copper nitrate and coffee powder extract taken in 1:3 ratio were subjected to microwave heating at $540 \mathrm{~W}$ for 7-8 min which produced a brownish-black precipitate at the end. The precipitate was centrifuged, filtered and then dried in hot air oven for 4-5 h.

\section{Antibacterial activity of $\mathrm{CuO}$ nanoparticles}

The antibacterial activity of $\mathrm{CuO}$ nanoparticles was tested against six human pathogenic microbes viz., Shigella dysenteriae 1, Vibrio cholerae non.0139 (L4), Vibrio cholerae non.0139 (CSK6669), Streptococcus pneumoniae, Staphylococcus aureus and Escherichia coli. The antimicrobial assay was done using the disc diffusion method. Solutions of $\mathrm{CuO}$ nanoparticles were prepared in water having different concentrations of $200,100,50$ and $1 \mu \mathrm{g} / \mathrm{disc}$. The test microorganisms (freshly cultured in Luria Britani broth) were seeded into respective medium (agar-agar) by spreading $40 \mu \mathrm{l}$ of each strain, using spread plate method. The autoclaved paper discs $(5 \mathrm{~mm}$ in diameter and $0.4 \mathrm{~mm}$ in thickness) were then placed in petri dishes of $100 \mathrm{~mm}$ diameter, containing test microorganisms in agar media, followed by addition of different concentrations of solutions in each disc. Water was applied as control for each solution. The plates were then incubated at $37{ }^{\circ} \mathrm{C}$ for overnight. The antimicrobial activities were evaluated by measuring the zone of inhibition in millimeters $(\mathrm{mm})$. The mean value of the readings was recorded after repeating each experiment three times.

\section{Results and discussion}

The formation of $\mathrm{CuO}$ nanoparticles from tea leaf extract was initially monitored by color change (Fig. 1). The SEM image clearly indicated the formation of spherical copper oxide nanoparticles with a size of $50-100 \mathrm{~nm}$ (Fig. 2). The UV-visible spectrum of $\mathrm{CuO}$ showed the absorption peak at $271 \mathrm{~nm}$ (Fig. 3) which was matched with the expected value of copper oxide nanoparticles [5]. Figure 4 shows the Fourier transform infrared spectroscopy (FTIR) peaks of

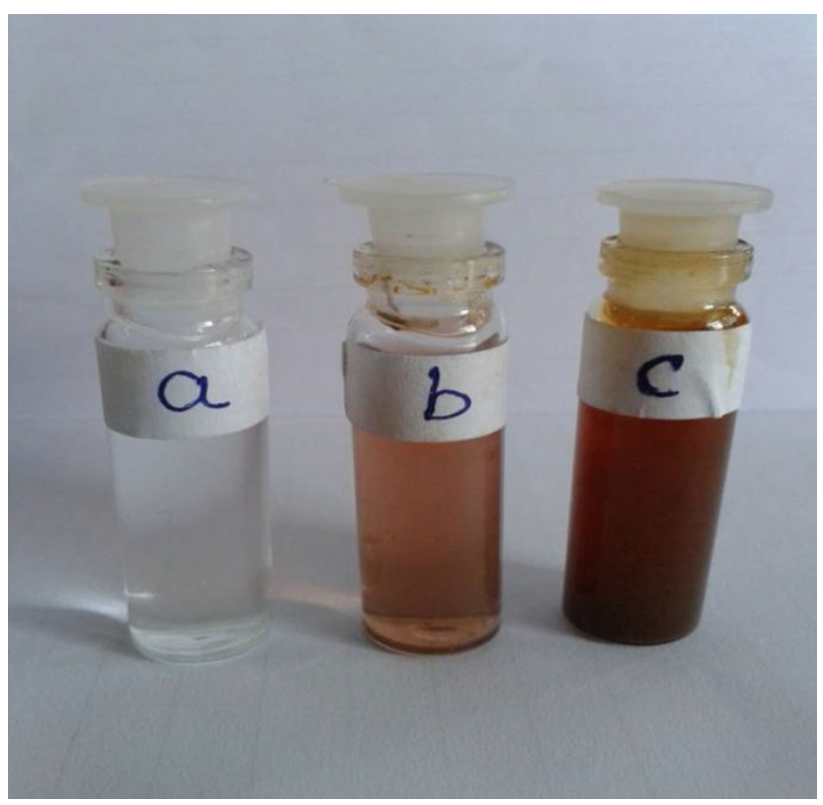

Fig. $1 a$ Aqueous solution of copper nitrate, $b$ aqueous extract of tea leaf, $c$ color of the solution after the reaction

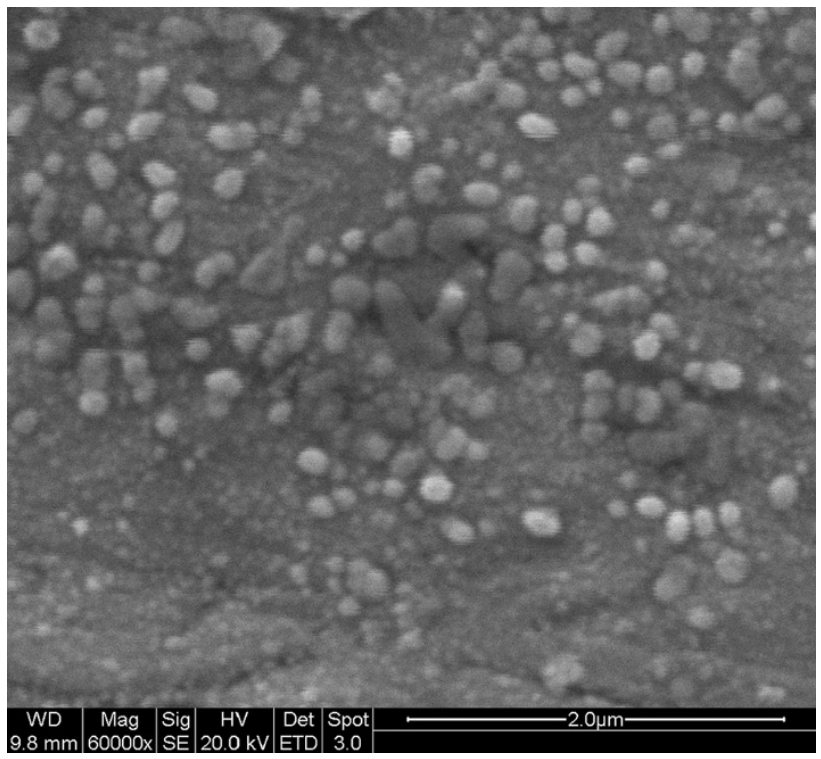

Fig. 2 SEM image of $\mathrm{CuO}$ using tea leaf extract 


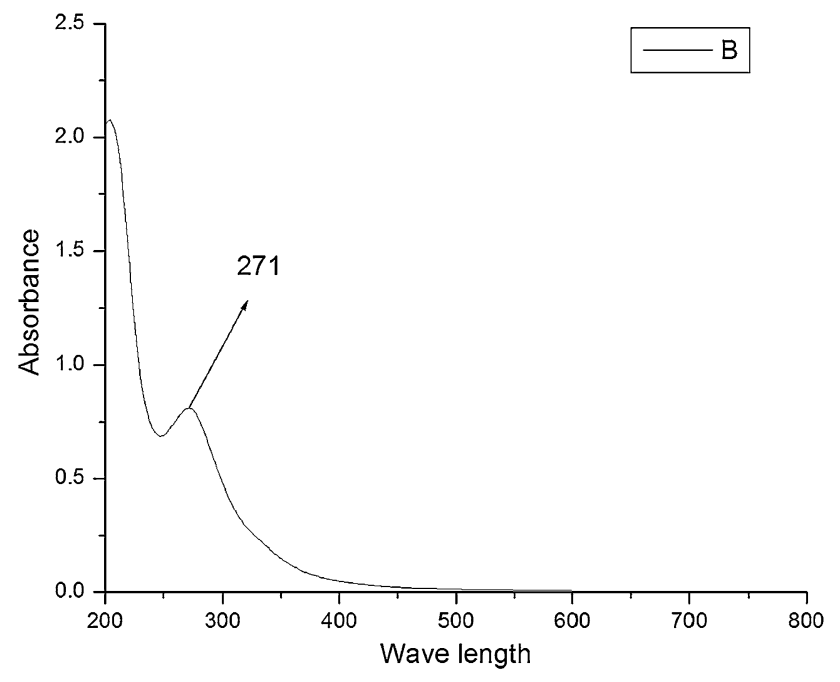

Fig. 3 UV-Vis spectra of $\mathrm{CuO}$ using tea leaf extract

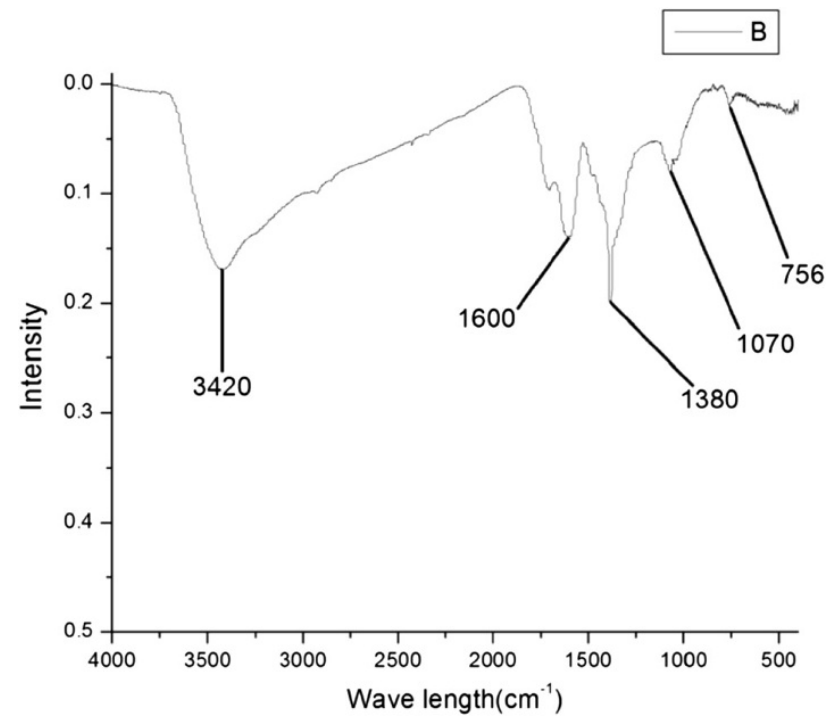

Fig. 4 IR spectra of $\mathrm{CuO}$ using tea leaf extract

$\mathrm{CuO}$ nanoparticles at $756,1,070,1,380,1,600$ and $3,420 \mathrm{~cm}^{-1}$. The peak at $1,070 \mathrm{~cm}^{-1}$ indicated the presence of $\mathrm{C}-\mathrm{O}$ stretching frequency, whereas the geminal methyl group showed its presence at $1,380 \mathrm{~cm}^{-1}$. The peak at $1,600 \mathrm{~cm}^{-1}$ represented the unreacted ketone group suggesting the presence of flavonones adsorbed on the surface of $\mathrm{CuO}$ nanoparticles. This suggests that watersoluble organic moieties of tea were responsible for the synthesis of $\mathrm{CuO}$. The FTIR spectrum also showed a broad absorption band at $3,420 \mathrm{~cm}^{-1}$ mainly for -OH groups present on the surface of the $\mathrm{CuO}$ nanostructures. The formation of $\mathrm{CuO}$ nanoparticles from coffee powder extract was initially observed through color change of the solution as shown in Fig. 5. Figure 6 shows the SEM image of $\mathrm{CuO}$ indicating the formation of spherical-shaped

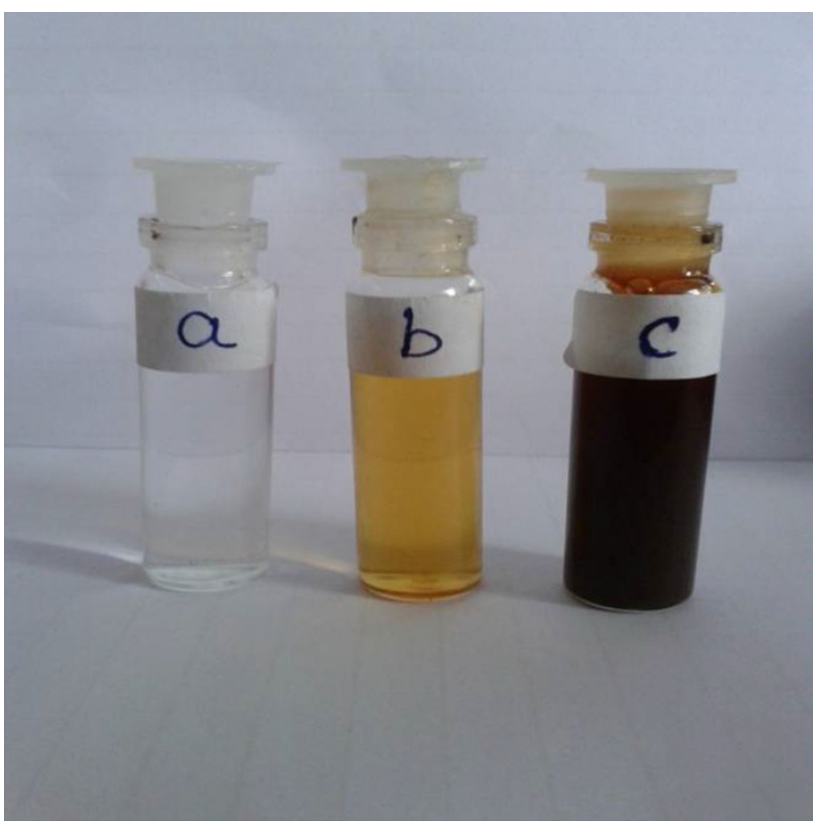

Fig. $5 a$ Aqueous solution of copper nitrate, $b$ aqueous extract of coffee powder, $c$ color of the solution after the reaction

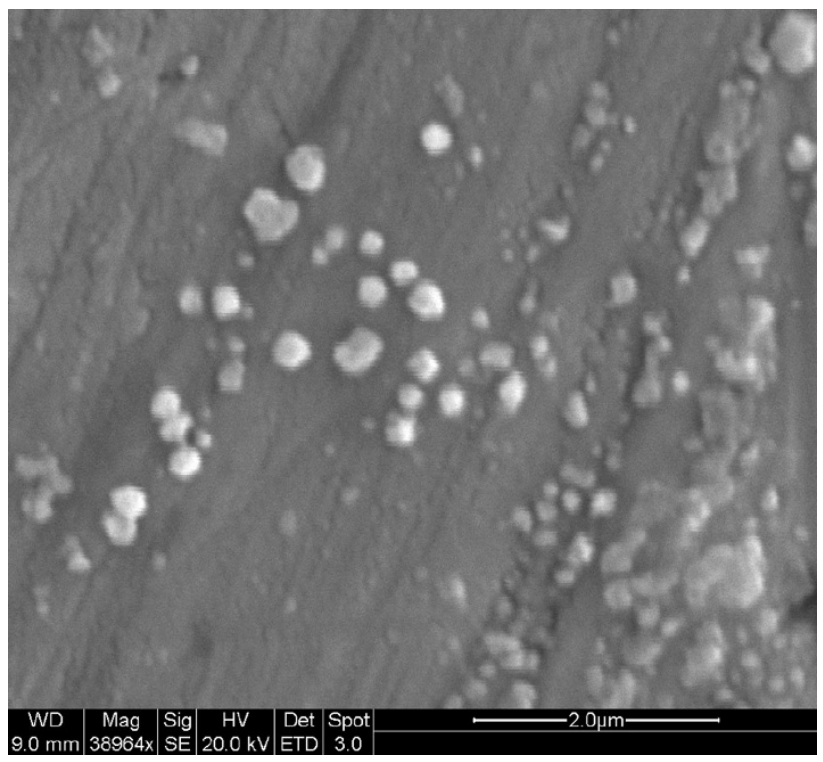

Fig. 6 SEM image of $\mathrm{CuO}$ using coffee extract

nanoparticles below $100 \mathrm{~nm}$. The UV-visible spectrum of $\mathrm{CuO}$ nanoparticles showed a strong absorption peak at $269 \mathrm{~nm}$ (Fig. 7), matching with the literature value. The FTIR spectrum given in Fig. 8 again confirmed the formation of $\mathrm{CuO}$ nanoparticles in presence of coffee extract, showing peaks at $482,1,080,1,370,1,620$ and $3,440 \mathrm{~cm}^{-1}$. This has again indicated the secretion of some water-soluble organic components from coffee, which might have contributed in the formation of copper oxide nanoparticles via similar mechanism. The microwave irradiation 


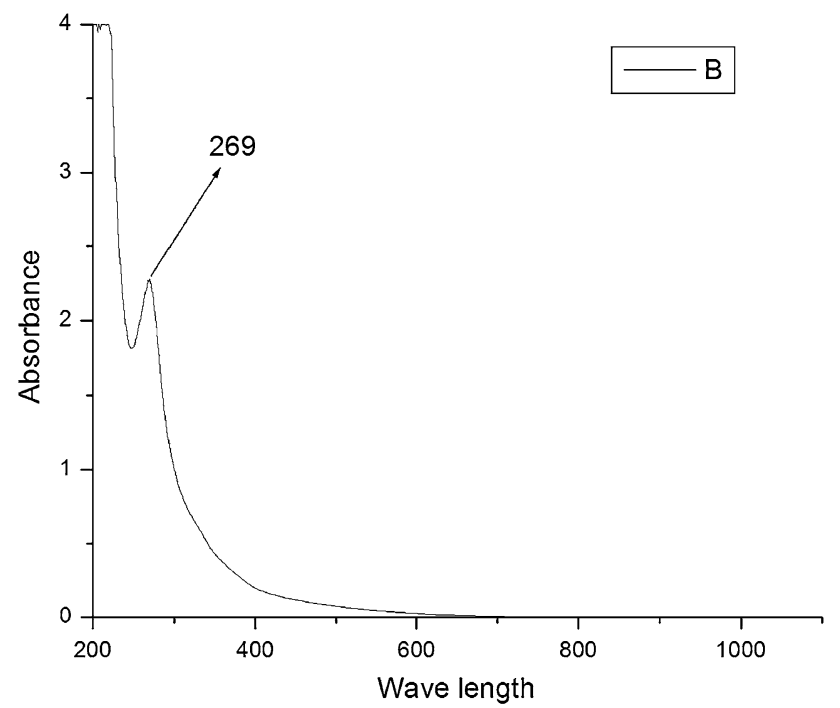

Fig. 7 UV-Vis spectra of $\mathrm{CuO}$ using coffee extract

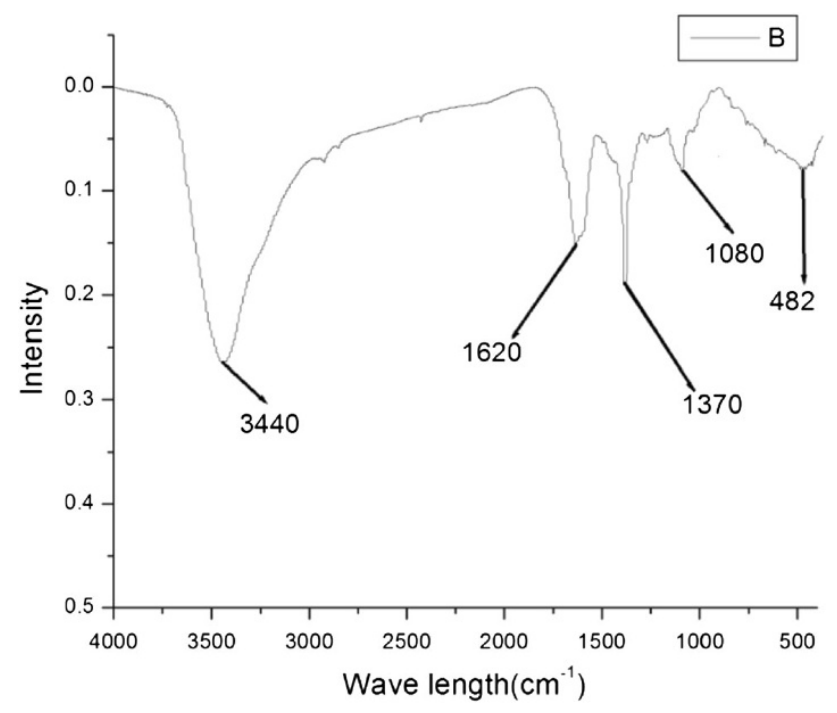

Fig. 8 IR spectra of $\mathrm{CuO}$ using coffee extract

Table 1 Results of antibiotic assay with $\mathrm{CuO}$ nanoparticles

\begin{tabular}{lllll}
\hline Test Microorganisms & \multicolumn{4}{l}{$\begin{array}{l}\text { Zone of Inhibition after 24 h incubation. } \\
(\mathrm{mm} \text { in 3 repeats } \pm \mathrm{SD})\end{array}$} \\
\cline { 2 - 5 } & $\mathrm{CuO}$ & & \\
\cline { 2 - 5 } & $\begin{array}{l}200 \\
(\mu \mathrm{g} / \mathrm{disc})\end{array}$ & $\begin{array}{l}100 \\
(\mu \mathrm{g} / \mathrm{disc})\end{array}$ & $\begin{array}{l}50 \\
(\mu \mathrm{g} / \mathrm{disc})\end{array}$ & $\begin{array}{l}1 \\
(\mu \mathrm{g} / \mathrm{disc})\end{array}$ \\
\hline $\begin{array}{l}\text { S. dysenteriae 1 } \\
\begin{array}{l}\text { V. cholerae } \\
\text { non.0139(L4) }\end{array}\end{array}$ & 12 & 7.5 & 6 & - \\
$\begin{array}{l}\text { V. cholerae } \\
\text { non.0139(CSK6669) }\end{array}$ & 12 & 8 & 6 & - \\
$\begin{array}{l}\text { S. flexneri } \\
\text { S. aureus }\end{array}$ & 9 & 7.5 & 7 & - \\
K. pneumoniae & 12 & 8 & 7 & - \\
\hline
\end{tabular}

accelerated the processes and the reactions were completed in very short period of time (7-8 min.). The reactions also gave products in absence of microwave heating but it took almost $4-5 \mathrm{~h}$ to complete the reaction. The possible mechanism is shown in the reaction Scheme 1. This gives strong evidence for the involvement of polyphenols in the rapid biosynthesis and for the stability of metallic nanoparticles in the aqueous medium [28]. It suggests that welldispersed copper nanoparticles may have obtained through the reduction of $\mathrm{Cu}^{2+}$ using tea leaf and coffee extracts which contains epigallocatechin gallate (EGCG). EGCG is a highly water-soluble compound with strong polarity and it has acted as both reducing and capping agent. As illustrated in Scheme 1, EGCG served as a stable (electron + proton) donor during interactions. It was first converted into the radical ion "semihydro-EGCG" and then into dehydro-EGCG through oxidation. DehydroEGCG and EGCG together constituted the redox system which was sufficient to reduce $\mathrm{Cu}^{2+}$ to $\mathrm{Cu}(0)$. The lone pair of electrons in the polar groups of EGCG might have occupied the two sp orbits of the copper ion to form a complex compound. Thus, EGCG was capped with the copper ions to synthesize $\mathrm{Cu}(0)$ nanoparticles through reduction of $\mathrm{Cu}^{2+}$ inside the nanoscopic templates. In the presence of nanoscopic templates, small copper nanoparticles were initially formed which on further oxidation gave copper oxide nanoparticles. There is always a need of the development of resistant strains of bacteria which has increased the need for new antibiotics [29, 30]. To recognize the potential of $\mathrm{CuO}$ nanoparticles as antimicrobial agent, we have studied the antibacterial activity of synthesized $\mathrm{CuO}$ nanoparticles against six human pathogenic bacteria. Experimental data in the present study suggested that these nanoparticles have antibacterial activity against all the pathogenic microbial strains in different concentrations, in the range of 5-16 $\mathrm{mm}$ zone of inhibition. But, it showed remarkable antibacterial activity $(12 \mathrm{~mm}$ inhibition zone with $200 \mu \mathrm{g} / \mathrm{disc}$ ) against, $S$. dysenteriae 1 and Vibrio cholerae non.0139, as shown in Table 1. The antibacterial activity of $\mathrm{CuO}$ nanoparticles may be attributed to the fact that the size of the bacterial cells is usually in the micron range which have cellular membranes containing pores in nanometer range. These nanoparticles may have size less than the pore size of the bacteria and thus, they have easily crossed the cell membrane without any hindrance.

\section{Conclusion}

In this paper, we have reported for the first time, the use of tea leaf and coffee powder extracts for the synthesis of $\mathrm{CuO}$ nanoparticles using water as solvent under microwave 
irradiations. The $\mathrm{CuO}$ nanoparticles were found to be spherical in shape with a size of 50-100 nm. The synthesized nanoparticles showed remarkable antibacterial activity against two pathogenic bacteria and thus can be used as promising antibacterial agents in future. The use of environmentally benign materials like plant extracts, for the synthesis of nanoparticles offers numerous benefits of eco-friendliness and compatibility. Besides, the applications of such nanoparticles in pharmaceutical and other biomedical applications make this method potentially use for the large-scale synthesis of other inorganic nanomaterials.

Acknowledgments Authors are grateful to Tripura University for antibacterial activity. Financial approval from CPRI, Bangalore is greatly acknowledged.

Open Access This article is distributed under the terms of the Creative Commons Attribution License which permits any use, distribution, and reproduction in any medium, provided the original author(s) and the source are credited.

\section{References}

1. Liu, J., Qiao, S.Z., Hu, Q.H.: Magnetic nanocomposites with mesoporous structures: synthesis and applications. Small 7, 425-443 (2011)

2. Luechinger, N.A., Grass, R.N., Athanassiou, E.K.: Bottom-up fabrication of metal/metal nanocomposites from nanoparticles of immiscible metals. Chem. Mater. 22, 155-160 (2010)

3. Mohanpuria, P., Rana, N.K., Yadav, S.K.: Biosynthesis of nanoparticle technological concepts and future applications. J. Nanopart. Res. 10, 507-517 (2008)

4. Honary, Soheyla, Barabadi, Hamed, Gharaei-Fathabad, Eshrat: Green synthesis of copper nanoparticles using penicillium aurantiogriseum, penicillium citrinum and penicillium citrinum and penicillium waksmani. Dig. J. Nanomater. Biostruct. 7, 999-1005 (2012)

5. Capek, I.: Preparation of metal nanoparticles in water-in-oil (w/o) microemulsions. Adv. Colloid Interface Sci. 110, 49-74 (2004)

6. Yin, B.S., Ma, H.Y., Wang, S.Y.: Electrochemical synthesis of silver nanoparticles under protection of poly $(N$-vinylpyrrolidone). J. Phys. Chem. B 107, 8898-8904 (2003)

7. Zhu, J.J., Liu, S.W., Palchik, O.: Shape-controlled synthesis of silver nanoparticles by pulse sonoelectrochemical methods. Langmuir 16, 6396-6399 (2000)

8. Vanaja, M., Gnanajobitha, G., Paulkumar, K., Rajeshkumar, S., Malrkodi, C., Annadurai, G.: Phytosynthesis of silver nanoparticles. J. Nanostruct. Chem. 3, 17 (2013)

9. Ghorbani, Hamid Raza: Biosynthesis of silver nanoparticles using Salmonella typhimurium. J. Nanostruct. Chem. 3, 43 (2013)

10. Mirjalili, Mohammad, Niloofar, Taghmari, Marjan, Mirjalili: Antibacterial properties of nano silver finish cellulose fabric. J. Nanostruct. Chem. 3, 43 (2013)

11. Gopinath, K., Gowri, S., Arumugam, A.: Phytosynthesis of silver nanoparticles using Pterocarpus santalinus leaf extract and their antibacterial properties. J. Nanostruct. Chem. 3, 68 (2013)
12. Abboud, Y., Eddahbi, A., El Bourari, A., Aitenneite, H., Brouzi, K., Mouslim, J.: Microwave-assisted approach for rapid and green phytosynthesis of silver nano particles using aqueous onion (Allium Cepa) extract and their antibacterial activity. J. Nanostruct. Chem. 3, 84 (2013)

13. Snoke, D.: Coherent exciton Waves. Science 273, 1351 (1996)

14. Briskman, R.N.: A study of electrodeposited cuprous oxide photovoltaic cells. Solar Energy Mater. Solar Cells 27, 361-368 (1992)

15. Li, X., Gao, H., Murphy, C.J.: Nanoindentation of $\mathrm{Cu}_{2} \mathrm{O}$ nanocubes. Nano Lett. 4, 1903-1907 (2004)

16. Liu, R., Oba, F., Bohannan, E.W.: Epitaxial electrodeposition of ordered $\mathrm{Cu}_{2} \mathrm{O}(110)$ nanostructures on $\operatorname{InP}(111)$. Chem. Mater. 17, 725-729 (2005)

17. Horiguchi, H.: Size-dependent antimicrobial properties of $\mathrm{CuO}$ nanoparticle against Gram-positive and -negative bacterial strains. Chem. Antimicrob. Agents 5, 46-59 (1980)

18. Ojas, M., Bhagat, M., Gopalakrishnan, C.: Ultrafine dispersed $\mathrm{CuO}$ nanoparticles and their antibacterial activity. J. Exp. Nanosci. 3, 185-193 (2008)

19. Li, B., Yu, S., Hwang, J.Y.: Synthesis of silver-treated bentonite: evaluation of its antibacterial properties. J. Miner. Mater. Charact. Eng. 1, 61-68 (2002)

20. Condorelli, G.G., Costanzo, I.L., Fragala, I.L.: A single photochemical route for the formation of both copper nanoparticles and patterned nanostructured films. J. Mater. Chem. 13, 2409-2411 (2003)

21. Yu, Y., Du, F.P., Yu, J.C.: One-dimensional shape-controlled preparation of porous $\mathrm{Cu}_{2} \mathrm{O}$ nano-whiskers by using $\mathrm{CTAB}$ as a template. J. Solid State Chem. 177, 4640-4647 (2004)

22. Huang, Lei, Peng, Feng, Yu, Hao: Diameter-controlling growth of solid-cored carbon nanofibers on a pulse plated iron nanocrystalline substrate in flames. Mater. Res. Bull. 43, 3397-3407 (2008)

23. Shin, Ho, Sun, Song, Jae, Yong, Yu, Jin: Template-assisted electrochemical synthesis of cuprous oxide nanowires. Mater. Lett. 63, 397-399 (2009)

24. Saha, Mitali, Das, Soma: Electrochemical studies of carbon nanotube obtained from coconut oil as non enzymatic glucose biosensor. Adv. Sci. Eng. Med. 5, 1-4 (2013)

25. Das, S., Saha, M.: Preparation of carbon nanosphere from bamboo and its use in water purification. Current Trends Technol. Sci. 2(1), 174-177 (2012)

26. Debbarma, Monica, Das, Soma, Saha, Mitali: Effect of reducing agents on the structure of zinc oxide under microwave irradiation. Adv. Manuf. 1, 183-186 (2013)

27. Sutradhar, P., Debnath, N., Saha, M.: Microwave-assisted rapid synthesis of alumina nanoparticles using tea, coffee and triphala extracts. Adv Manuf. (2013). doi:10.1007/s40436-013-0043-0

28. Xiong, J., Wang, Y., Xue, Q.: Synthesis of highly stable dispersions of nanosized copper particles using L-ascorbic acid. Green Chem. 13, 900-904 (2011)

29. Zakaria, Z.A., Sufian, A.S., Ramasamy, K.: In vitro antimicrobial activity of Muntingia calabura extracts and fractions. Afr. J. Microbiol. Res. 4, 304-307 (2010)

30. Eloff, J.N.: A sensitive and quick microplate method to determine the minimal inhibitory concentration of plant extracts for bacteria. Planta Med. 64, 711-713 (1998) 